University of Massachusetts Amherst

ScholarWorks@UMass Amherst

Resource Economics Department Faculty

Publication Series

Resource Economics

2006

\title{
Modeling generator power plant portfolios and pollution taxes in electric power supply chain networks: A transportation network equilibrium transformation
}

$\mathrm{KWu}$

A Nagurney

ZG Liu

JK Stranlund

Follow this and additional works at: https://scholarworks.umass.edu/resec_faculty_pubs

\section{Recommended Citation}

Wu, K; Nagurney, A; Liu, ZG; and Stranlund, JK, "Modeling generator power plant portfolios and pollution taxes in electric power supply chain networks: A transportation network equilibrium transformation" (2006). Transportation Research Part D-Transport and Environment. 186.

DOI: $10.1016 / j . \operatorname{trd} .2006 .01 .002$

This Article is brought to you for free and open access by the Resource Economics at ScholarWorks@UMass Amherst. It has been accepted for inclusion in Resource Economics Department Faculty Publication Series by an authorized administrator of ScholarWorks@UMass Amherst. For more information, please contact scholarworks@library.umass.edu. 


\title{
Modeling generator power plant portfolios and pollution taxes in electric power supply chain networks: A transportation network equilibrium transformation
}

\author{
Kai Wu a , Anna Nagurney ${ }^{\text {b,c,*, Zugang Liu }}{ }^{\text {c }}$, John K. Stranlund ${ }^{\mathrm{d}}$ \\ ${ }^{a}$ Department of Mechanical and Industrial Engineering, University of Massachusetts, Amherst, MA 01003, United States \\ ${ }^{\mathrm{b}}$ Radcliffe Institute for Advanced Study, 34 Concord Avenue, Harvard University, \\ Cambridge, MA 02138, United States \\ ${ }^{\mathrm{c}}$ Department of Finance and Operations Management, Isenberg School of Management, University of Massachusetts, \\ Amherst, MA 01003, United States \\ ${ }^{\mathrm{d}}$ Department of Resource Economics, College of Natural Resources and the Environment, University of Massachusetts, \\ Amherst, MA 01003, United States
}

\begin{abstract}
Global climate change and fuel security risks have encouraged international and regional adoption of pollution/carbon taxes. A major portion of such policy interventions is directed at the electric power industry with taxes applied according to the type of fuel used by the power generators in their power plants. This paper proposes an electric power supply chain network model that captures the behavior of power generators faced with a portfolio of power plant options and subject to pollution taxes. We demonstrate that this general model can be reformulated as a transportation network equilibrium model with elastic demands and qualitatively analyzed and solved as such. The connections between these two different modeling schemas is done through finite-dimensional variational inequality theory. The numerical examples illustrate how changes in the pollution/carbon taxes affect the equilibrium electric power supply chain network production outputs, the transactions between the various decision-makers the demand market prices, as well as the total amount of carbon emissions generated.
\end{abstract}

(C) 2006 Elsevier Ltd. All rights reserved.

Keywords: Electric power; Supply chains; Pollution taxes; Transportation network equilibrium; Variational inequalities

\section{Introduction}

The ubiquity of electricity in the industrialized world obscures the scale, impacts, and ongoing economic transformation of this vital sector. In modern societies there are few goods or services that do not depend

\footnotetext{
* Corresponding author. Address: Radcliffe Institute for Advanced Study, 34 Concord Avenue, Harvard University, Cambridge, MA 02138, United States.

E-mail address: nagurney@gbfin.umass.edu (A. Nagurney). 
directly on electricity. In the past half-century, the total annual electricity use in the US alone has grown every year but two. Other statistics of scale include the US electrical industry's more than half a trillion dollars of net assets, its $\$ 220$ billion in annual sales, and its consumption of almost $40 \%$ of domestic primary energy (coal, natural gas, uranium, and oil), or approximately 40 quadrillion BTU (see Edison Electric Institute, 2000; Energy Information Administration, 2000, 2005). In addition to the great economic and industrial impacts of electric power, the heavy reliance on fossil fuel sources before conversion to electricity has had concomitantly a large environmental impact. Of the total US emissions of carbon dioxide and nitrous oxide, more than a third arises from generating electricity. With the accumulating evidence of global warming, any policy aimed at mitigating the immense risks of unstable climate must directly address the electricity industry (Poterba, 1993; Cline, 1992).

Currently, market prices for energy fail to signal its many external costs (e.g., regional and global pollution) and also hide market distortions such as subsidies. In order to address such market failures in energy, a powerful policy is that of pollution taxes, specifically, carbon taxes (Baranzini et al., 2000), and encouraging generation from renewable sources (e.g., solar power and wind power, Painuly, 2001) through the use of credits (e.g., tradable green certificates). The latter policy instrument is now deployed in several states in the US, as well as in the European Union (see RECS, 1999; Schaeffer et al., 1999).

Hence, the modeling of the options available to power generators in terms of their power plant selection (and associated fuel) plus environmental taxes is of great interest in the electric power industry. A suitable model, however, must also be able to accommodate changing economic behavior due to the deregulation of the electric power industry, from the historic norm of highly regulated, vertically integrated utilities to a new environment of competition between the major players, such as power generators, suppliers, transmission service providers, and consumers. For additional background on the electric power industry (see Casazza and Delea, 2003; Singh, 1999; Zaccour, 1998).

\section{The electric power supply chain network model with power plants and pollution taxes}

In this section we develop the electric power supply chain network model that includes power plants as well as pollution taxes. We consider $G$ power generators (or gencos), each of which generally owns and operates $M$ power plants. Each power plant may use a different primary energy fuel (i.e., coal, natural gas, uranium, oil, sun, wind, etc.) and we can expect that each may have different associated costs. Furthermore, as we shall illuminate, subsequently, each plant will have associated costs that fully reflect policy objectives. For example, a coal plant and a natural gas plant, even if they have identical functions for electric power production may have very different carbon or pollution taxes, as is expected, given their markedly different environmental impacts (burning coal being far dirtier environmentally than burning natural gas). There are also $S$ power suppliers, $T$ transmission service providers, and $K$ consumer markets, as depicted in Fig. 1 . The majority of the needed notation is given in Table 1 . An equilibrium solution is denoted by “**”. All vectors are assumed to be column vectors, except where noted otherwise.

The top tiered nodes in the electric power supply chain network in Fig. 1, enumerated by $1, \ldots, g \ldots, G$, represent the $G$ electric power generators, who are the decision-makers who own and operate the electric power generating facilities or power plants denoted by the second tier of nodes in the network. The gencos produce electric power using the different power plants and sell to the power suppliers in the third tier. Node $g m$ in the second tier corresponds to genco $g$ 's power plant $m$, with the second tier of nodes enumerated as: $11, \ldots, G M$. We assume that each electric power generator seeks to determine his optimal production portfolio across his power plants and his sales allocations of the electric power to the suppliers in order to maximize his own profit.

Power suppliers, which are represented by the third tiered nodes in Fig. 1, function as intermediaries. The nodes corresponding to the power suppliers are enumerated as: $1, \ldots, s, \ldots, S$ with node $s$ corresponding to supplier $s$. They purchase electric power from the power generators and are aware as to the types of power plants used by the generators. They also sell the electric power to the consumers at the different demand markets. We assume that the power suppliers compete with one another in a noncooperative manner. However, the suppliers do not physically possess electric power at any stage of the supplying process; they only hold and trade the right for the electric power. 


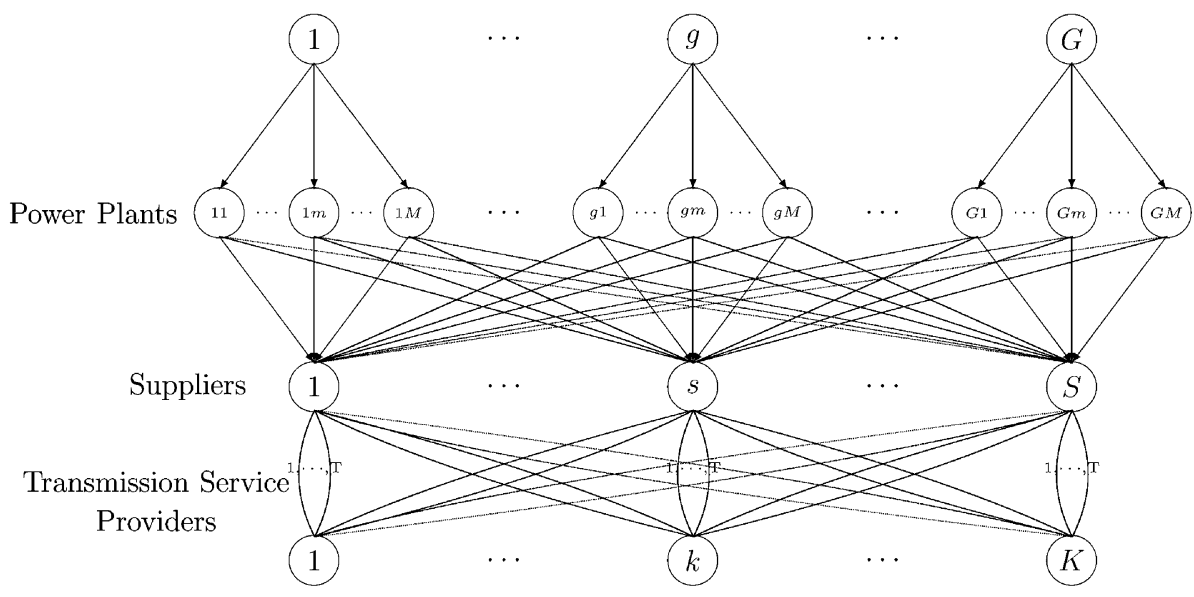

Demand Markets

Fig. 1. The electric power supply chain network.

Table 1

Notation for the electric power supply chain network model

\begin{tabular}{|c|c|}
\hline Notation & Definition \\
\hline$q_{g m}$ & Quantity of electricity produced by generator $g$ using power plant $m$, where $g=1, \ldots, G ; m=1, \ldots, M$ \\
\hline$q_{m}$ & $G$-dimensional vector of electric power generated by the gencos using power plant $m$ with components: $g_{1 m}, \ldots, g_{G m}$ \\
\hline$q$ & $G M$-dimensional vector of all the electric power outputs generated by the gencos at the power plants \\
\hline$Q^{1}$ & $\begin{array}{l}G M S \text {-dimensional vector of electric power flows between the power plants of the power generators and the } \\
\text { power suppliers with component gms denoted by } q_{g m s}\end{array}$ \\
\hline$Q^{2}$ & $\begin{array}{l}S T K \text {-dimensional vector of power flows between suppliers and demand markets with component } s t k \text { denoted } \\
\text { by } q_{s k}^{t} \text { and denoting the flow between supplier } s \text { and demand market } k \text { via transmission provider } t\end{array}$ \\
\hline$d$ & $K$-dimensional vector of market demands with component $k$ denoted by $d_{k}$ \\
\hline$f_{g m}\left(q_{m}\right)$ & $\begin{array}{l}\text { Power generating cost function of power generator } g \text { using power plant } m \text { with marginal power generating cost } \\
\text { with respect to } q_{g m} \text { denoted by } \frac{\partial f_{g m}}{\partial q_{g m}}\end{array}$ \\
\hline$c_{g m s}\left(q_{g m s}\right)$ & $\begin{array}{l}\text { Transaction cost incurred by power generator } g \text { using power plant } m \text { in transacting with power supplier } s \text { with } \\
\text { marginal transaction cost denoted by } \frac{\partial c_{g m s}\left(q_{g m s}\right)}{\partial q_{g m s}}\end{array}$ \\
\hline$\tau_{g m}$ & Unit tax associated with carbon emissions by genco $g$ using power plant $m$ \\
\hline$e_{g m}$ & Amount of carbon emitted by genco $g$ using power plant $m$ per unit of electric power produced \\
\hline$h$ & $\begin{array}{l}S \text {-dimensional vector of the power suppliers' supplies of the electric power with component } s \text { denoted } \\
\text { by } h_{s} \text {, with } h_{s} \equiv \sum_{g=1}^{G} \sum_{m=1}^{M} q_{g m s}\end{array}$ \\
\hline$c_{s}(h) \equiv c_{s}\left(Q^{1}\right)$ & $\begin{array}{l}\text { Operating cost of power supplier } s \text { with marginal operating cost with respect to } h_{s} \text { denoted by } \frac{\partial c_{s}}{\partial h_{s}} \text { and the marginal } \\
\text { operating cost with respect to } q_{g m s} \text { denoted by } \frac{\partial c_{s}\left(Q^{1}\right)}{\partial q_{g m s}}\end{array}$ \\
\hline$c_{s k}^{t}\left(q_{s k}^{t}\right)$ & $\begin{array}{l}\text { Transaction cost incurred by power supplier } s \text { in transacting with demand market } k \text { via transmission } \\
\text { provider } t \text { with marginal transaction cost with respect to } q_{s k}^{t} \text { denoted by } \frac{\partial c_{s k}^{t}\left(q_{s k}^{t}\right)}{\partial q_{s k}^{s}}\end{array}$ \\
\hline$\hat{\mathrm{c}}_{g m s}\left(q_{g m s}\right)$ & $\begin{array}{l}\text { Transaction cost incurred by power supplier } s \text { in transacting with power generator } g \text { for power generated } \\
\text { by plant } m \text { with marginal transaction cost denoted by } \frac{\partial \hat{c}_{g m s}\left(q_{g m s}\right)}{\partial q_{o m s}}\end{array}$ \\
\hline$\hat{c}_{s k}^{t}\left(Q^{2}\right)$ & $\begin{array}{l}\text { Unit transaction cost incurred by consumers at demand market } k \text { in transacting with power } \\
\text { supplier } s \text { via transmission provider } t\end{array}$ \\
\hline$\rho_{3 k}(d)$ & Demand market price function at demand market $k$ \\
\hline
\end{tabular}

The bottom tiered nodes in Fig. 1 represent the demand markets, which can be distinguished from one another by their geographic locations or the type of associated consumers such as whether they correspond, for example, to businesses or to households. There are $K$ bottom-tiered nodes with node $k$ corresponding to demand market $k$. 
A transmission service is necessary for the physical delivery of electric power from the power generators to the points of consumption. The transmission service providers are the entities who own and operate the electric power transmission and distribution systems, and distribute electric power from power generators to the consumption markets. However, since these transmission service providers do not make decisions such as to where or from whom the electric power will be delivered, they are not explicitly represented by nodes in this network model. We, instead, as suggested by Nagurney and Matsypura (2004), model them as different modes of transaction corresponding to the parallel links connecting a given supplier node to a given demand market node in Fig. 1. Hence, an implicit assumption is that the power suppliers need to cover the direct cost and decide which transmission service providers should be used and how much electric power should be delivered. The structure of the network in Fig. 1 guarantees that the conservation of flow equations associated with the electric power production and distribution are satisfied. The flows on the links joining the genco nodes in Fig. 1 to the power plant nodes are respectively: $q_{11}, \ldots, q_{g m}, \ldots, q_{G M}$; the flows on the links from the power plant nodes to the supplier nodes are given, respectively, by the components of the vector $Q^{1}$, whereas the flows on the links joining the supplier nodes with the demand markets are given by the respective components of the vector: $Q^{2}$.

Of course, if a particular genco does not own $M$ power plants, then the corresponding links (and nodes) can just be removed from the electric supply chain network in Fig. 1 and the notation reduced accordingly.

We now describe the behavior of the electric power generators, the suppliers, and the consumers at the demand markets. We then state the equilibrium conditions of the electric power supply chain network and provide the variational inequality formulation.

\subsection{The behavior of the power generators and their optimality conditions}

We assume that $e_{g m}, g=1, \ldots, G ; m=1, \ldots, M$, denotes the carbon emissions generated per unit of electric power produced by genco $g$ using its power plant $m$. Hence, the total amount of carbon emissions associated with genco $g$ and power plant $m$ is $e_{g m} q_{g m}$.

Let $\rho_{1 g m s}^{*}$ denote the unit price charged by power generator $g$ for the transaction with power supplier $s$ for power produced at plant $m . \rho_{1 g m s}^{*}$ is an endogenous variable and can be determined once the complete electric power supply chain network equilibrium model is solved. Since we have assumed that each individual power generator is a profit-maximizer, the optimization problem of power generator $g$ can be expressed as follows:

$$
\begin{aligned}
\text { Maximize } & \sum_{m=1}^{M} \sum_{s=1}^{S} \rho_{1 g m s}^{*} q_{g m s}-\sum_{m=1}^{M} f_{g m}\left(q_{m}\right)-\sum_{m=1}^{M} \sum_{s=1}^{S} c_{g m s}\left(q_{g m s}\right)-\sum_{m=1}^{M} \tau_{g m} e_{g m} q_{g m} \\
\text { subject to: } & \sum_{s=1}^{S} q_{g m s}=q_{g m}, \quad m=1, \ldots, M, \\
& q_{g m s} \geqslant 0, \quad m=1, \ldots, M ; s=1, \ldots, S .
\end{aligned}
$$

The first term in the objective function (1) represents the revenue and the next two terms represent the power generation cost and transaction costs, respectively. The last term in (1) denotes the total payout in pollution taxes by the genco based on the total carbon pollution emitted. We note that Nagurney and Toyasaki (2003) assumed that pollution generated associated with producers in a supply chain had a similar structure, although in that paper no environmental policies in the form of pollution taxes were considered. Conservation of flow equation (2) states that the amount of power generated at a particular power plant (and corresponding to a particular genco) is equal to the electric power transacted by the genco from that power plant with all the suppliers and this holds for each of the power plants.

Note that, according to the power generation cost functions $f_{g m}\left(q_{m}\right), g=1, \ldots, G ; m=1, \ldots, M$, the cost depends not only on the specific power plant's output using the particular plant-type but may also on the outputs of the other power generators using the same power plant-type. This is reasonable due to competition for the resources that are used in the various electric power plant production processes. Of course, this model contains, as a special case, power generating cost functions such that $f_{g m}\left(q_{g m}\right), g=1, \ldots, G ; m=1, \ldots, M$, in which case the power generating cost associated with a power generator and a power plant depends only upon 
the output of the generator's particular power plant. Hence, in this case, the model would assume perfect competition in the input markets. It is important to note that the proposed modeling framework can handle either imperfect or perfect competition in the input markets.

We assume that the generating cost and the transaction cost functions for each power generator are continuously differentiable and convex, and that the power generators compete in a noncooperative manner in the sense of Nash (1950, 1951). The optimality conditions for all power generators simultaneously, under the above assumptions (Gabay and Moulin, 1980; Bazaraa et al., 1993; Bertsekas and Tsitsiklis, 1989; Nagurney, 1993), coincide with the solution of the following variational inequality: determine $\left(q^{*}, Q^{1 *}\right) \in \mathscr{K}^{1}$ satisfying

$$
\begin{aligned}
& \sum_{g=1}^{G} \sum_{m=1}^{M}\left[\frac{\partial f_{g m}\left(q_{m}^{*}\right)}{\partial q_{g m}}+\tau_{g m} e_{g m}\right] \times\left[q_{g m}-q_{g m}^{*}\right]+\sum_{g=1}^{G} \sum_{m=1}^{M} \sum_{s=1}^{S}\left[\frac{\partial c_{g m s}\left(q_{g m s}^{*}\right)}{\partial q_{g m s}}-\rho_{1 g m s}^{*}\right] \times\left[q_{g m s}-q_{g m s}^{*}\right] \\
& \quad \geqslant 0 \quad \forall\left(q, Q^{1}\right) \in \mathscr{K}^{1},
\end{aligned}
$$

where $\mathscr{K}^{1} \equiv\left\{\left(q, Q^{1}\right) \mid\left(q, Q^{1}\right) \in R_{+}^{G M+G M S}\right.$ and (2) holds $\}$.

\subsection{The behavior of power suppliers and their optimality conditions}

The power suppliers, such as the power marketers, traders, and brokers, in turn, are involved in transactions both with the power generators and with the consumers at demand markets through the transmission service providers.

Since electric power cannot be stored, it is reasonable to assume that the total amount of electricity sold by a power supplier is equal to the total electric power that he purchased from the generators and produced via the different power plants available to the generators. This assumption can be expressed as the following conservation of flow equations:

$$
\sum_{k=1}^{K} \sum_{t=1}^{T} q_{s k}^{t}=\sum_{g=1}^{G} \sum_{m=1}^{M} q_{g m s}, \quad s=1, \ldots, S .
$$

Let $\rho_{2 s k}^{t *}$ denote the price charged by power supplier $s$ to demand market $k$ via transmission service provider $t$. This price is determined endogenously in the model once the entire network equilibrium problem is solved. As noted above, it is assumed that each power supplier seeks to maximize his own profit. Hence the optimization problem faced by supplier $s$ may be expressed as follows:

$$
\begin{array}{ll}
\text { Maximize } & \sum_{k=1}^{K} \sum_{t=1}^{T} \rho_{2 s k}^{t *} q_{s k}^{t}-c_{s}\left(Q^{1}\right)-\sum_{g=1}^{G} \sum_{m=1}^{M} \rho_{1 g m s}^{*} q_{g m s}-\sum_{g=1}^{G} \sum_{m=1}^{M} \hat{c}_{g m s}\left(q_{g m s}\right)-\sum_{k=1}^{K} \sum_{t=1}^{T} c_{s k}^{t}\left(q_{s k}^{t}\right) \\
\text { subject to: } & \sum_{k=1}^{K} \sum_{t=1}^{T} q_{s k}^{t}=\sum_{g=1}^{G} \sum_{m=1}^{M} q_{g m s}, \\
& q_{g m s} \geqslant 0, \quad g=1, \ldots, G ; m=1, \ldots, M, \\
& q_{s k}^{t} \geqslant 0, \quad k=1, \ldots, K ; t=1, \ldots, T .
\end{array}
$$

The first term in (6) denotes the revenue of supplier $s$; the second term denotes the operating cost of the supplier; the third term denotes the payments for the electric power to the various gencos, and the final two terms represent the various transaction costs. Note that here we have assumed imperfect competition in terms of the handling cost but, of course, if the handling cost functions $c_{s}, s=1, \ldots, S$, depend only on the electric power handled by $s$ (and not also on the power handled by the other suppliers), then the dependence of these functions on $Q^{1}$ can be simplified accordingly (and this is a special case of the model). The latter would reflect perfect competition.

We assume that the transaction costs and the operating costs (6) are all continuously differentiable and convex, and that the power suppliers compete in a noncooperative manner. Hence, the optimality conditions for all suppliers, simultaneously, under the above assumptions (Dafermos and Nagurney, 1987; Nagurney et al., 2002; Nagurney and Matsypura, 2004), can be expressed as the following variational inequality: determine $\left(Q^{2 *}, Q^{1 *}\right) \in \mathscr{K}^{2}$ such that 


$$
\begin{aligned}
& \sum_{s=1}^{S} \sum_{k=1}^{K} \sum_{t=1}^{T}\left[\frac{\partial c_{s k}^{t}\left(q_{s k}^{t *}\right)}{\partial q_{s k}^{t}}-\rho_{2 s k}^{t *}\right] \times\left[q_{s k}^{t}-q_{s k}^{t *}\right]+\sum_{g=1}^{G} \sum_{m=1}^{M} \sum_{s=1}^{S}\left[\frac{\partial c_{s}\left(Q^{1 *}\right)}{\partial q_{g m s}}+\frac{\partial \hat{c}_{g m s}\left(q_{g m s}^{*}\right)}{\partial q_{g m s}}+\rho_{1 g m s}^{*}\right] \\
& \quad \times\left[q_{g m s}-q_{g m s}^{*}\right] \geqslant 0 \quad \forall\left(Q^{2}, Q^{1}\right) \in \mathscr{K}^{2},
\end{aligned}
$$

where $\mathscr{K}^{2} \equiv\left\{\left(Q^{2}, Q^{1}\right) \mid\left(Q^{2}, Q^{1}\right) \in R_{+}^{S T K+G M S}\right.$ and holds $\}$.

In addition, for notational convenience, we let

$$
h_{s} \equiv \sum_{g=1}^{G} \sum_{m=1}^{M} q_{g m s}, \quad s=1, \ldots, S .
$$

As defined in Table 1, the operating cost of power supplier $s, c_{s}$, is a function of the total electricity inflows to the power supplier, that is:

$$
c_{s}(h) \equiv c_{s}\left(Q^{1}\right), \quad s=1, \ldots, S .
$$

Hence, his marginal cost with respect to $h_{s}$ is equal to the marginal cost with respect to $q_{g m s}$ :

$$
\frac{\partial c_{s}(h)}{\partial h_{s}} \equiv \frac{\partial c_{s}\left(Q^{1}\right)}{\partial q_{g m s}}, \quad s=1, \ldots, S, m=1, \ldots, M .
$$

After the substitution of (11) and (13) into (10), and algebraic simplification, we obtain a variational inequality equivalent to (10), as follows: determine $\left(h^{*}, Q^{2 *}, Q^{1 *}\right) \in \mathscr{K}^{3}$ such that

$$
\begin{aligned}
& \sum_{s=1}^{S} \frac{\partial c_{s}\left(h^{*}\right)}{\partial h_{s}} \times\left[h_{s}-h_{s}^{*}\right]+\sum_{s=1}^{S} \sum_{k=1}^{K} \sum_{t=1}^{T}\left[\frac{\partial c_{s k}^{t}\left(q_{s k}^{t *}\right)}{\partial q_{s k}^{t}}-\rho_{2 s k}^{t *}\right] \times\left[q_{s k}^{t}-q_{s k}^{t *}\right]+\sum_{g=1}^{G} \sum_{m=1}^{M} \sum_{s=1}^{S}\left[\frac{\partial \hat{c}_{g m s}\left(q_{g m s}^{*}\right)}{\partial q_{g m s}}+\rho_{1 g m s}^{*}\right] \\
& \quad \times\left[q_{g m s}-q_{g m s}^{*}\right] \geqslant 0 \quad \forall\left(h, Q^{1}, Q^{2},\right) \in \mathscr{K}^{3},
\end{aligned}
$$

where $\mathscr{K}^{3} \equiv\left\{\left(h, Q^{2}, Q^{1}\right) \mid\left(h, Q^{2}, Q^{1}\right) \in R_{+}^{S(1+T K+G M)}\right.$ and (7) and (11) hold $\}$.

\subsection{Equilibrium conditions for the demand markets}

At each demand market $k$ the following conservation of flow equation must be satisfied:

$$
d_{k}=\sum_{s=1}^{S} \sum_{t=1}^{T} q_{s k}^{t}, \quad k=1, \ldots, K .
$$

Since the demand market price functions are given (instead of the demand functions as was the case in Nagurney and Matsypura, 2004), the market equilibrium conditions at demand market $k$ take the form: for each power supplier $s, s=1, \ldots, S$, and transaction mode $t, t=1, \ldots, T$,

$$
\rho_{2 s k}^{t *}+\hat{c}_{s k}^{t}\left(Q^{2 *}\right) \begin{cases}=\rho_{3 k}\left(d^{*}\right) & \text { if } q_{s k}^{t *}>0, \\ \geqslant \rho_{3 k}\left(d^{*}\right) & \text { if } q_{s k}^{t *}=0 .\end{cases}
$$

The interpretation of conditions (16) is as follows: consumers at a demand market will purchase power from a supplier via a transmission provider, provided that the purchase price plus the unit transaction cost is equal to the price that the consumers are willing to pay at that demand market. If the purchase price plus the unit transaction cost exceeds the price the consumers are willing to pay, then there will be no transaction between that supplier and demand market via that transmission provider. The equivalent variational inequality takes the form: determine $\left(Q^{2 *}, d^{*}\right) \in \mathscr{K}^{4}$, such that

$$
\sum_{s=1}^{S} \sum_{k=1}^{K} \sum_{t=1}^{T}\left[\rho_{2 s k}^{t *}+\hat{c}_{s k}^{t}\left(Q^{2 *}\right)\right] \times\left[q_{s k}^{t}-q_{s k}^{t *}\right]-\sum_{k=1}^{K} \rho_{3 k}\left(d^{*}\right) \times\left[d_{k}-d_{k}^{*}\right] \geqslant 0 \quad \forall\left(Q^{2}, d\right) \in \mathscr{K}^{4},
$$

where $\mathscr{K}^{4} \equiv\left\{\left(Q^{2}, d\right) \mid\left(Q^{2}, d\right) \in R_{+}^{K(S T+1)}\right.$ and (15) holds $\}$. 


\subsection{The equilibrium conditions for the electric power supply chain network}

In equilibrium, the optimality conditions for all the power generators, the optimality conditions for all the power suppliers, and the equilibrium conditions for all the demand markets must be simultaneously satisfied so that no decision-maker has any incentive to alter his transactions. We now formally state the equilibrium conditions for the entire electric power supply chain network.

Definition 1 (Electric power supply chain network equilibrium). The equilibrium state of the electric power supply chain network with power plants and pollution taxes is one where the electric power flows between the tiers of the network coincide and the electric power flows satisfy the sum of conditions (4), (14), and (17).

We now state and prove:

Theorem 1 (Variational inequality formulation of the electric power supply chain network equilibrium). The equilibrium conditions governing the electric power supply chain network according to Definition 1 coincide with the solution of the variational inequality given by: determine $\left(q^{*}, h^{*}, Q^{1 *}, Q^{2 *}, d^{*}\right) \in \mathscr{K}^{5}$ satisfying:

$$
\begin{aligned}
& \sum_{g=1}^{G} \sum_{m=1}^{M}\left[\frac{\partial f_{g m}\left(q_{m}^{*}\right)}{\partial q_{g m}}+\tau_{g m} e_{g m}\right] \times\left[q_{g m}-q_{g m}^{*}\right]+\sum_{s=1}^{S} \frac{\partial c_{s}\left(h^{*}\right)}{\partial h_{s}} \\
& \quad \times\left[h_{s}-h_{s}^{*}\right]+\sum_{g=1}^{G} \sum_{m=1}^{M} \sum_{s=1}^{S}\left[\frac{\partial c_{g m s}\left(q_{g m s}^{*}\right)}{\partial q_{g m s}}+\frac{\partial \hat{c}_{g m s}\left(q_{g m s}^{*}\right)}{\partial q_{g m s}}\right] \times\left[q_{g m s}-q_{g m s}^{*}\right]+\sum_{s=1}^{S} \sum_{k=1}^{K} \sum_{t=1}^{T}\left[\frac{\partial c_{s k}^{t}\left(q_{s k}^{t *}\right)}{\partial q_{s k}^{t}}+\hat{c}_{s k}^{t}\left(Q^{2 *}\right)\right] \\
& \quad \times\left[q_{s k}^{t}-q_{s k}^{t *}\right]-\sum_{k=1}^{K} \rho_{3 k}\left(d^{*}\right) \times\left[d_{k}-d_{k}^{*}\right] \geqslant 0 \quad \forall\left(q, h, Q^{1}, Q^{2}, d\right) \in \mathscr{K}^{5}
\end{aligned}
$$

where

$$
\mathscr{K}^{5} \equiv\left\{\left(q, h, Q^{1}, Q^{2}, d\right) \mid\left(q, h, Q^{1}, Q^{2}, d\right) \in R_{+}^{G M+S+G M S+T S K+K} \text { and (2), (5), (11), and (15) hold }\right\} .
$$

Proof. We first prove that an equilibrium according to Definition 1 coincides with the solution of variational inequality (18). Indeed, summation of (4), (14), and (17), after algebraic simplifications, yields (18).

We now prove the converse, that is, a solution to variational inequality (18) satisfies the sum of conditions (4), (14), and (17), and is, therefore, an electric power supply chain network equilibrium pattern according to Definition 1.

First, we add the term $\rho_{1 g m s}^{*}-\rho_{1 g m s}^{*}$ to the first term in the third summand expression in (18). Then, we add the term $\rho_{2 s k}^{t *}-\rho_{2 s k}^{t *}$ to the first term in the fourth summand expression in (18). Since these terms are all equal to zero, they do not change (18). Hence, we obtain the following inequality:

$$
\begin{aligned}
& \sum_{g=1}^{G} \sum_{m=1}^{M}\left[\frac{\partial f_{g m}\left(q_{m}^{*}\right)}{\partial q_{g m}}+\tau_{g m} e_{g m}\right] \times\left[q_{g m}-q_{g m}^{*}\right]+\sum_{s=1}^{S} \frac{\partial c_{s}\left(h^{*}\right)}{\partial h_{s}} \times\left[h_{s}-h_{s}^{*}\right]+\sum_{g=1}^{G} \sum_{m=1}^{M} \\
& \quad \times \sum_{s=1}^{S}\left[\frac{\partial c_{g m s}\left(q_{g m s}^{*}\right)}{\partial q_{g m s}}+\frac{\partial \hat{c}_{g m s}\left(q_{g m s}^{*}\right)}{\partial q_{g m s}}+\rho_{1 g m s}^{*}-\rho_{1 g m s}^{*}\right] \times\left[q_{g m s}-q_{g m s}^{*}\right]+\sum_{s=1}^{S} \sum_{k=1}^{K} \\
& \quad \times \sum_{t=1}^{T}\left[\frac{\partial c_{s k}^{t}\left(q_{s k}^{t *}\right)}{\partial q_{s k}^{t}}+\hat{c}_{s k}^{t}\left(q_{s k}^{t *}\right)+\rho_{2 s k}^{t *}-\rho_{2 s k}^{t *}\right] \times\left[q_{s k}^{t}-q_{s k}^{t *}\right]-\sum_{k=1}^{K} \rho_{3 k}\left(d^{*}\right) \times\left[d_{k}-d_{k}^{*}\right] \geqslant 0 \\
& \quad \forall\left(q, h, Q^{1}, Q^{2}, d\right) \in \mathscr{K}^{5},
\end{aligned}
$$

which can be rewritten as

$$
\sum_{g=1}^{G} \sum_{m=1}^{M}\left[\frac{\partial f_{g m}\left(q_{m}^{*}\right)}{\partial q_{g m}}+\tau_{g m} e_{g m}\right] \times\left[q_{g m}-q_{g m}^{*}\right]+\sum_{g=1}^{G} \sum_{m=1}^{M} \sum_{s=1}^{S}\left[\frac{\partial c_{g m s}\left(q_{g m s}^{*}\right)}{\partial q_{g m s}}-\rho_{1 g m s}^{*}\right] \times\left[q_{g m s}-q_{g m s}^{*}\right]
$$




$$
\begin{aligned}
& +\sum_{s=1}^{S} \frac{\partial c_{s}\left(h^{*}\right)}{\partial h_{s}} \times\left[h_{s}-h_{s}^{*}\right]+\sum_{s=1}^{S} \sum_{k=1}^{K} \sum_{t=1}^{T}\left[\frac{\partial c_{s k}^{t}\left(q_{s k}^{t *}\right)}{\partial q_{s k}^{t}}-\rho_{2 s k}^{t *}\right] \times\left[q_{s k}^{t}-q_{s k}^{t *}\right]+\sum_{s=1}^{S} \sum_{m=1}^{M} \sum_{g=1}^{G} \\
& \times\left[\frac{\partial \hat{c}_{g m s}\left(q_{g m s}^{*}\right)}{\partial q_{g m s}}+\rho_{1 g m s}^{*}\right] \times\left[q_{g m s}-q_{g m s}^{*}\right]+\sum_{s=1}^{S} \sum_{k=1}^{K} \sum_{t=1}^{T}\left[\rho_{2 s k}^{t *}+\hat{c}_{s k}^{t}\left(q_{s k}^{t *}\right)\right] \\
& \times\left[q_{s k}^{t}-q_{s k}^{t *}\right]-\sum_{k=1}^{K} \rho_{3 k}\left(d^{*}\right) \times\left[d_{k}-d_{k}^{*}\right] \geqslant 0 \quad \forall\left(q, h, Q^{1}, Q^{2}, d\right) \in \mathscr{K}^{5} .
\end{aligned}
$$

Clearly, (20) is the sum of the optimality conditions (4) and (14), and the equilibrium conditions (20) and is, hence, according to Definition 1 an electric power supply chain network equilibrium.

We now describe how to recover the prices associated with the first and third tiers of nodes in the electric power supply chain network. Clearly, the components of the vector $\rho_{3}^{*}$ can be directly obtained from the solution to variational inequality (18). We now describe how to recover the prices $\rho_{1 g m s}^{*}$, for all $g, m, s$, and $\rho_{2 s k}^{t *}$ for all $s, k, t$, from the solution of variational inequality (18). The prices associated with the power suppliers can be obtained by setting $((16)) \rho_{2 s k}^{t *}=\rho_{3 k}^{*}-\hat{c}_{s k}^{t}\left(Q^{2 *}\right)$ for any $s, t, k$ such that $q_{s k}^{t *}>0$. The top-tiered prices, in turn, can be recovered by setting $((4)) \rho_{1 g m s}^{*}=\frac{\partial f_{g m}\left(q_{m}^{*}\right)}{\partial q_{g m s}}+\tau_{g m} e_{g m}+\frac{\partial c_{g m s}\left(q_{g m s}^{*}\right)}{\partial q_{g m s}}$ for any $g, m, s$ such that $q_{g m s}^{*}>0$.

Nagurney and Matsypura (2004) derived a variational inequality formulation of electric power supply chain network equilibrium in the case of known demand functions but since the conservation of flow expression (7) in their model was an inequality the formulation also had Lagrange multipliers reflecting nodal prices associated with those inequalities as variables in their variational inequality. Also, the models of Nagurney and Matsypura (2004) and Nagurney and Liu (2005) did not include power plants and had no pollution taxes for policy decision-making.

Note that the total carbon emissions generated by genco $g$ can be obtained once variational inequality (18) is solved. We denote the total amount of carbon emitted by genco $g$ by $\mathrm{TE}_{g}$ and we have that $\mathrm{TE}_{g}=\sum_{m=1}^{M} e_{g m} q_{g m}^{*}$. The total amount of carbon emitted by all the power generators, denoted by TE, is then: $\mathrm{TE}=\sum_{g=1}^{G} T E_{g}=\sum_{g=1}^{G} \sum_{m=1}^{M} e_{g m} q_{g m}^{*}$.

Remark. For simplicity and definiteness, here we have considered the terms $\tau_{g m}, g=1, \ldots, G ; m=1, \ldots, M$, to be pollution taxes, and, hence, their values are nonnegative. If one wishes to model a pollution credit for production with a "clean" production technique (consider, for example, power production by wind farms) then $\tau_{g m}$ would be a subsidy that takes on a negative value. The emission terms: $e_{g m}, g=1, \ldots, G$; $m=1, \ldots, M$, would no longer be used but, instead, mathematically, these terms would be set identically equal to one to reflect the fact that a clean production subsidy must be attached to output instead of emissions. All the above results would mathematically still hold true.

\section{The transportation network equilibrium model with elastic demands}

In this section, we recall the transportation network equilibrium model with elastic demands, due to Dafermos (1982), in which the travel disutility functions are assumed known and given. In Section 4, we will then establish that the electric power supply chain network model in Section 2 can be reformulated as such a transportation network equilibrium problem but over a specially constructed network topology.

\subsection{Transportation network equilibrium model}

We consider a network $\mathscr{G}$ with the set of links $L$ with $K$ elements, the set of paths $P$ with $Q$ elements, and the set of origin/destination (O/D) pairs $W$ with $Z$ elements. We denote the set of paths joining O/D pair $w$ by $P_{w}$. Links are denoted by $a, b$, etc; paths by $p, q$, etc., and O/D pairs by $w_{1}, w_{2}$, etc.

We denote the flow on path $p$ by $x_{p}$ and the flow on link $a$ by $f_{a}$. The user travel cost on a link $a$ is denoted by $c_{a}$ and the user travel cost on a path $p$ by $C_{p}$. We denote the travel demand associated with traveling between O/D pair $w$ by $d_{w}$ and the travel disutility by $\lambda_{w}$. 
The link flows are related to the path flows through the following conservation of flow equations:

$$
f_{a}=\sum_{p \in P} x_{p} \delta_{a p} \quad \forall a \in L
$$

where $\delta_{a p}=1$ if link $a$ is contained in path $p$, and $\delta_{a p}=0$, otherwise. Hence, the flow on a link is equal to the sum of the flows on paths that contain that link.

The user costs on paths are related to user costs on links through the following equations:

$$
C_{p}=\sum_{a \in L} c_{a} \delta_{a p} \quad \forall p \in P,
$$

that is, the user cost on a path is equal to the sum of user costs on links that make up the path.

For the sake of generality, we allow the user cost on a link to depend upon the entire vector of link flows, denoted by $f$, so that

$$
c_{a}=c_{a}(f) \quad \forall a \in L .
$$

We have the following conservation of flow equations:

$$
\sum_{p \in P_{w}} x_{p}=d_{w} \quad \forall w .
$$

Also, assume, as given, disutility functions, such that

$$
\lambda_{w}=\lambda_{w}(d) \quad \forall w,
$$

where $d$ is the vector of travel demands with travel demand associated with O/D pair $w$ being denoted by $d_{w}$.

Definition 2 (Transportation network equilibrium). In equilibrium, the following conditions must hold for each O/D pair $w \in W$ and each path $p \in P_{w}$ :

$$
C_{p}\left(x^{*}\right)-\lambda_{w}\left(d^{*}\right) \begin{cases}=0 & \text { if } x_{p}^{*}>0, \\ \geqslant 0 & \text { if } x_{p}^{*}=0 .\end{cases}
$$

The interpretation of conditions (26) is that only those paths connecting an O/D pair are used that have minimal travel costs and those costs are equal to the travel disutility associated with traveling between that O/D pair. As proved in Dafermos (1982), the transportation network equilibrium conditions (26) are equivalent to the following variational inequality in path flows: determine $\left(x^{*}, d^{*}\right) \in \mathscr{K}^{6}$ such that

$$
\sum_{w \in W} \sum_{p \in P_{w}} C_{p}\left(x^{*}\right) \times\left[x_{p}-x_{p}^{*}\right]-\sum_{w \in W} \lambda_{w}\left(d^{*}\right) \times\left[d_{w}-d_{w}^{*}\right] \geqslant 0 \quad \forall(x, d) \in \mathscr{K}^{6},
$$

where $\mathscr{K}^{6} \equiv\left\{(x, d) \mid(x, d) \in R_{+}^{K+Z}\right.$ and $\left.d_{w}=\sum_{p \in P_{w}} x_{p}, \forall w\right\}$.

We now recall the equivalent variational inequality in link form due to Dafermos (1982).

Theorem 2. A link flow pattern and associated travel demand pattern is a transportation network equilibrium if and only if it satisfies the variational inequality problem: determine $\left(f^{*}, d^{*}\right) \in \mathscr{K}^{7}$ satisfying

$$
\sum_{a \in L} c_{a}\left(f^{*}\right) \times\left(f_{a}-f_{a}^{*}\right)-\sum_{w \in W} \lambda_{w}\left(d^{*}\right) \times\left(d_{w}-d_{w}^{*}\right) \geqslant 0 \quad \forall(f, d) \in \mathscr{K}^{7},
$$

where $\mathscr{K}^{7} \equiv\left\{(f, d) \in R_{+}^{K+Z} \mid\right.$ there exists an $x$ satisfying (21) and $\left.d_{w}=\sum_{p \in P_{w}} x_{p} \forall w\right\}$.

Beckmann et al. (1956) were the first to formulate rigorously the transportation network equilibrium conditions (26) in the context of user link cost functions and travel disutility functions that admitted symmetric Jacobian matrices so that the equilibrium conditions (26) coincided with the Kuhn-Tucker optimality conditions of an appropriately constructed optimization problem. The variational inequality formulation, in turn, allows for asymmetric functions. 


\section{Transportation network equilibrium reformulation of the electric power supply chain network equilibrium model}

In this section, we show that the electric power supply chain network equilibrium model presented in Section 2 is isomorphic to a properly configured transportation network equilibrium model through the establishment of a supernetwork equivalence of the former.

\subsection{Supernetwork equivalence of the electric power supply chain network}

We now establish the supernetwork equivalence of the electric power supply chain network equilibrium model to the transportation network equilibrium model with known travel disutility functions described in Section 3. This transformation allows us, as we will demonstrate in Section 5, to apply algorithms developed for the latter class of problems to solve the former.

Consider an electric power supply chain network with power plants as discussed in Section 2 with given power generators: $g=1, \ldots, G$; given power plants for each power generator: $m=1, \ldots, M$; power suppliers: $s=1, \ldots, S$; transmission service providers: $t=1, \ldots, T$, and demand markets: $k=1, \ldots, K$. The supernetwork, $\mathscr{G}_{\mathscr{S}}$, of the isomorphic transportation network equilibrium model is depicted in Fig. 2 and is constructed as follows.

It consists of six tiers of nodes with the origin node 0 at the top or first tier and the destination nodes at the sixth or bottom tier. Specifically, $\mathscr{G}_{\mathscr{S}}$ consists of a single origin node 0 at the first tier, and $K$ destination nodes at the bottom tier, denoted, respectively, by: $z_{1}, \ldots, z_{K}$. There are $K \mathrm{O} / \mathrm{D}$ pairs in $\mathscr{G}_{\mathscr{S}}$ denoted by $w_{1}=$ $\left(0, z_{1}\right), \ldots, w_{k}=\left(0, z_{k}\right), \ldots, w_{K}=\left(0, z_{K}\right)$. Node 0 is connected to each second tiered node $x_{g}, g=1, \ldots, G$,

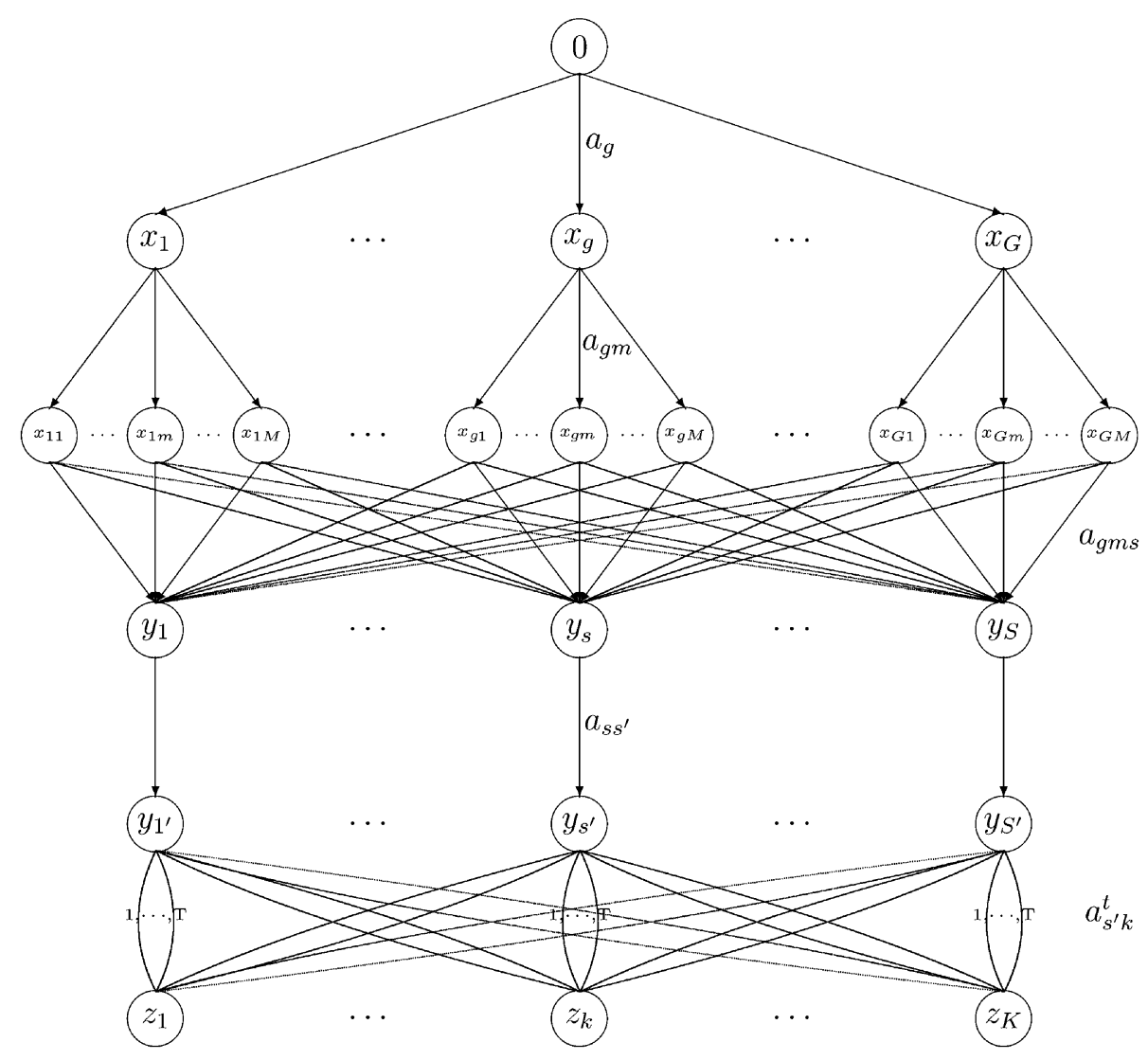

Fig. 2. The $\mathscr{G}_{\mathscr{S}}$ supernetwork representation of electric power network equilibrium. 
by a single link. Each second tiered node $x_{g}$, in turn, is connected to each third tiered node $x_{g m}, g=1, \ldots, G$; $m=1, \ldots, M$, by a single link, and each third tiered node is then connected to each fourth-tiered node $y_{s}$, $s=1, \ldots, S$, by a single link. Each fourth tiered node $y_{s}$ is connected to the corresponding fifth tiered node $y_{s^{\prime}}$ by a single link. Finally, each fifth tiered node $y_{s^{\prime}}$ is connected to each destination node $z_{k}, k=1, \ldots, K$, at the sixth tier by $T$ parallel links.

Hence, in $\mathscr{G}_{\mathscr{S}}$, there are $G+G M+2 S+K+1$ nodes; $G+G M+G M S+S+S T K$ links, $K$ O/D pairs, and $G M S T K$ paths. We now define the link and link flow notation. Let $a_{g}$ denote the link from node 0 to node $x_{g}$ with associated link flow $f_{a_{g}}$, for $g=1, \ldots, G$. Let $a_{g m}$ denote the link from node $x_{g}$ to node $x_{g m}$ with link flow $f_{a_{g m}}$ for $g=1, \ldots, G ; m=1, \ldots, M$. Also, let $a_{g m s}$ denote the link from node $x_{g m}$ to node $y_{s}$ with associated link flow $f_{a_{g m s}}$ for $g=1, \ldots, G, m=1, \ldots, M$, and $s=1, \ldots, S$. Let $a_{s s^{\prime}}$ denote the link connecting node $y_{s}$ with node $y_{s^{\prime}}$ with associated link flow $f_{a_{\mathrm{s}^{\prime}}}$ for $s ; s^{\text {prime }}=1, \ldots, S$. Finally, let $a_{s^{\prime} k}^{t}$ denote the $t$-th link joining node $y_{s^{\prime}}$ with node $z_{k}$ for $s^{\prime}=1^{\prime}, \ldots, S^{\prime}, t=1, \ldots, T$, and $k=1, \ldots, K$ and with associated link flow $f_{a_{s^{\prime}}}$.

We group the link flows into the vectors as follows: we group the $\left\{f_{a_{g}}\right\}$ into the vector $f^{1}$; the $\left\{f_{a_{g m}}\right\}$ into the vector $f^{2}$, the $\left\{f_{a_{g m s}}\right\}$ into the vector $f^{3}$; the $\left\{f_{a_{s s^{s}}}\right\}$ into the vector $f^{4}$, and the $\left\{f_{a_{s^{\prime} k}}\right\}$ into the vector $f^{5}$.

Thus, a typical path connecting $\mathrm{O} / \mathrm{D}$ pair $w_{k}=\left(0, z_{k}\right)$, is denoted by $p_{\text {gmss' }}^{t}{ }_{s^{\prime} k}$ and consists of five links: $a_{g}, a_{g m}, a_{g m s}, a_{s s^{\prime}}$, and $a_{s^{\prime} k}^{t}$. The associated flow on the path is denoted by $x_{p_{g m s s^{\prime} k}^{t}}$. Finally, we let $d_{w_{k}}$ be the demand associated with O/D pair $w_{k}$ where $\lambda_{w_{k}}$ denotes the travel disutility for $w_{k}$.

Note that the following conservation of flow equations must hold on the network $\mathscr{G}_{\mathscr{S}}$ :

$$
\begin{aligned}
& f_{a_{g}}=\sum_{m=1}^{M} \sum_{s=1}^{S} \sum_{s^{\prime}=1}^{S^{\prime}} \sum_{k=1}^{K} \sum_{t=1}^{T} x_{p_{g m s s^{\prime} k}^{t}}, \quad g=1, \ldots, G, \\
& f_{a_{g m}}=\sum_{s=1}^{S} \sum_{s^{\prime}=1}^{S^{\prime}} \sum_{k=1}^{K} \sum_{t=1}^{T} x_{p_{g m s s^{\prime} k}^{t}}, \quad g=1, \ldots, G ; m=1, \ldots, M, \\
& f_{a_{g m s}}=\sum_{s^{\prime}=1}^{S^{\prime}} \sum_{k=1}^{K} \sum_{t=1}^{T} x_{p_{g m s^{\prime} k}^{t}}, \quad g=1, \ldots, G ; m=1, \ldots, M ; s=1, \ldots, S, \\
& f_{a_{s s^{\prime}}}=\sum_{g=1}^{G} \sum_{m=1}^{M} \sum_{k=1}^{K} \sum_{t=1}^{T} x_{p_{g m s s^{\prime} k}^{t}}, \quad s=1, \ldots, S ; s^{\prime}=1, \ldots, S^{\prime}, \\
& f_{a_{s^{\prime} k}}=\sum_{g=1}^{G} \sum_{m=1}^{M} \sum_{s=1}^{S} x_{p_{g m s s^{\prime} k}}, \quad s^{\prime}=1, \ldots, S^{\prime} ; t=1, \ldots, T ; k=1, \ldots, K .
\end{aligned}
$$

Also, we have that

$$
d_{w_{k}}=\sum_{g=1}^{G} \sum_{m=1}^{M} \sum_{s=1}^{S} \sum_{s^{\prime}=1}^{S^{\prime}} \sum_{t=1}^{T} x_{p_{g m s s^{\prime} k}^{t}}, \quad k=1, \ldots, K .
$$

If all path flows are nonnegative and (29)-(34) are satisfied, the feasible path flow pattern induces a feasible link flow pattern.

We can construct a feasible link flow pattern for $\mathscr{G}_{\mathscr{S}}$ based on the corresponding feasible electric power supply chain flow pattern in the electric power supply chain network model, $\left(q, h, Q^{1}, Q^{2}, d\right) \in \mathscr{K}^{5}$, thus:

$$
\begin{aligned}
& q_{g} \equiv f_{a_{g}}, \quad g=1, \ldots, G, \\
& q_{g m} \equiv f_{a_{g m}}, \quad g=1, \ldots, G ; m=1, \ldots, M, \\
& q_{g m s} \equiv f_{a_{g m s}}, \quad g=1, \ldots, G ; m=1, \ldots, M ; s=1, \ldots, S, \\
& h_{s} \equiv f_{a_{s s^{\prime}}}, \quad s=1, \ldots, S ; s^{\prime}=1^{\prime}, \ldots, S^{\prime}, \\
& q_{s k}^{t}=f_{a_{s^{\prime} k}}, \quad s=1, \ldots, S ; s^{\prime}=1^{\prime}, \ldots, S^{\prime} ; t=1, \ldots, T ; k=1, \ldots, K, \\
& d_{k}=\sum_{s=1}^{S} \sum_{t=1}^{T} q_{s k}^{t}, \quad k=1, \ldots, K .
\end{aligned}
$$


Observe that although $q_{g}$ is not explicitly stated in the model in Section 2, it is inferred in that

$$
q_{g}=\sum_{m=1}^{M} q_{g m}, \quad g=1, \ldots, G,
$$

and simply represents the total electric power produced by genco $g$.

Note that if $\left(q, Q^{1}, h, Q^{2}, d\right)$ is feasible then the link flow and demand pattern constructed according to (35)-(40) is also feasible and the corresponding path flow pattern which induces this link flow (and demand) pattern is also feasible.

We now assign user (travel) costs on the links of the network $\mathscr{G}_{\mathscr{S}}$ as follows: with each link $a_{g}$ we assign a user cost $c_{a_{g}}$ defined by

$$
\begin{aligned}
& c_{a_{g}} \equiv 0, \quad g=1, \ldots, G, \\
& c_{a_{g m}} \equiv \frac{\partial f_{g m}}{\partial q_{g m}}+\tau_{g m} e_{g m}, \quad g=1, \ldots, G ; m=1, \ldots, M,
\end{aligned}
$$

with each link $a_{g m s}$ we assign a user cost $c_{a_{g m s}}$ defined by

$$
c_{a_{g m s}} \equiv \frac{\partial c_{g m s}}{\partial q_{g m s}}+\frac{\partial \hat{c}_{g m s}}{\partial q_{g m s}}, \quad g=1, \ldots, G ; m=1, \ldots, M ; s=1, \ldots, S,
$$

with each link $s s^{\prime}$ we assign a user cost defined by

$$
c_{a_{s s^{\prime}}} \equiv \frac{\partial c_{s}}{\partial h_{s}}, \quad s=1, \ldots, S ; s^{\prime}=1, \ldots, S^{\prime} .
$$

Finally, for each link $a_{s^{\prime} k}^{t}$ we assign a user cost defined by

$$
c_{a_{s^{\prime} k}} \equiv \frac{\partial c_{s k}^{t}}{\partial q_{s k}^{t}}+\hat{c}_{s k}^{t}, \quad s=1, \ldots, S ; s^{\prime}=1, \ldots, S^{\prime} ; t=1, \ldots, T ; k=1, \ldots, K .
$$

Then a user of path $p_{\text {gmss }}^{t}$, for $g=1, \ldots, G ; m=1, \ldots, M ; s=1, \ldots, S ; s^{\prime}=1^{\prime}, \ldots, S^{\prime} ; t=1, \ldots, T$; $k=1, \ldots, K$, on network $\mathscr{G}_{\mathscr{S}}$ in Fig. 2 experiences a path travel cost $C_{p_{\text {gmss' }}^{t} k}$ given by

$$
C_{p_{g m s s^{\prime} k}^{t}}=c_{a_{g}}+c_{a_{g m}}+c_{a_{g m s}}+c_{a_{s s^{\prime}}}+c_{a_{s^{\prime} k}^{t}}=\frac{\partial f_{g m}}{\partial q_{g m}}+\tau_{g m} e_{g m}+\frac{\partial c_{g m s}}{\partial q_{g m s}}+\frac{\partial \hat{c}_{g m s}}{\partial q_{g m s}}+\frac{\partial c_{s}}{\partial h_{s}}+\frac{\partial c_{s k}^{t}}{\partial q_{s k}^{t}}+\hat{c}_{s k}^{t} .
$$

Also, we assign the (travel) demands associated with the O/D pairs as follows:

$$
d_{w_{k}} \equiv d_{k}, \quad k=1, \ldots, K,
$$

and the (travel) disutilities:

$$
\lambda_{w_{k}} \equiv \rho_{3 k}, \quad k=1, \ldots, K .
$$

Consequently, the equilibrium conditions (26) for the transportation network equilibrium model on the network $\mathscr{G}_{\mathscr{S}}$ state that for every O/D pair $w_{k}$ and every path connecting the O/D pair $w_{k}$ :

$$
C_{p_{g m s s^{\prime} k}^{t}}-\lambda_{w_{k}}=\frac{\partial f_{g m}}{\partial q_{g m}}+\tau_{g m} e_{g m}+\frac{\partial c_{g m s}}{\partial q_{g m s}}+\frac{\partial \hat{c}_{g m s}}{\partial q_{g m s}}+\frac{\partial c_{s}}{\partial h_{s}}+\frac{\partial c_{s k}^{t}}{\partial q_{s k}^{t}}+\hat{c}_{s k}^{t}-\lambda_{w_{k}} \begin{cases}=0 & \text { if } x_{p_{g m s s^{\prime} k}^{*}}^{*}>0, \\ 0 & \text { if } x_{p_{g m s s^{\prime} k}^{*}}^{*}=0 .\end{cases}
$$

We now show that the variational inequality formulation of the equilibrium conditions (50) in link form as in (28) is equivalent to the variational inequality (18) governing the electric power supply chain network equilibrium. For the transportation network equilibrium problem on $\mathscr{G}_{\mathscr{S}}$, according to Theorem 2 , we have that a link flow and travel disutility pattern $\left(f^{*}, d^{*}\right) \in \mathscr{K}^{7}$ is an equilibrium (according to (50)), if and only if it satisfies the variational inequality: 


$$
\begin{aligned}
& \sum_{g=1}^{G} c_{a_{g}}\left(f^{1 *}\right) \times\left(f_{a_{g}}-f_{a_{g}}^{*}\right)+\sum_{g=1}^{G} \sum_{m=1}^{M} c_{a_{g m}}\left(f^{2 *}\right) \times\left(f_{a_{g m}}-f_{a_{g m}}^{*}\right)+\sum_{g=1}^{G} \sum_{m=1}^{M} \sum_{s=1}^{S} c_{a_{g m s}}\left(f^{3 *}\right) \times\left(f_{a_{g m s}}-f_{a_{g m s}}^{*}\right) \\
& \quad+\sum_{s=1}^{S} \sum_{s^{\prime}=1}^{S^{\prime}} c_{a_{s s^{\prime}}}\left(f^{4 *}\right) \times\left(f_{a_{s s^{\prime}}}-f_{a_{s s^{\prime}}}^{*}\right)+\sum_{s^{\prime}=1}^{S^{\prime}} \sum_{k=1}^{K} \sum_{t=1}^{T} c_{a_{s^{\prime} k}^{t}}\left(f^{5 *}\right) \times\left(f_{a_{s^{\prime} k}^{t}}-f_{a_{s^{\prime} k}}^{*}\right) \\
& \quad-\sum_{k=1}^{K} \lambda_{w_{k}}\left(d^{*}\right) \times\left(d_{w_{k}}-d_{w_{k}}^{*}\right) \geqslant 0 \quad \forall(f, d) \in \mathscr{K}^{7} .
\end{aligned}
$$

After the substitution of (35)-(46) and (48)-(49) into (51), we have the following variational inequality: determine $\left(q^{*}, h^{*}, Q^{1 *}, Q^{2 *}, d^{*}\right) \in \mathscr{K}^{5}$ satisfying:

$$
\begin{aligned}
& \sum_{g=1}^{G} \sum_{m=1}^{M}\left[\frac{\partial f_{g m}\left(q_{m}^{*}\right)}{\partial q_{g m}}+\tau_{g m} e_{g m}\right] \times\left[q_{g m}-q_{g m}^{*}\right]+\sum_{s=1}^{S} \frac{\partial c_{s}\left(h^{*}\right)}{\partial h_{s}} \times\left[h_{s}-h_{s}^{*}\right]+\sum_{g=1}^{G} \sum_{m=1}^{M} \\
& \quad \times \sum_{s=1}^{S}\left[\frac{\partial c_{g m s}\left(q_{g m s}^{*}\right)}{\partial q_{g m s}}+\frac{\partial \hat{c}_{g m s}\left(q_{g m s}^{*}\right)}{\partial q_{g m s}}\right] \times\left[q_{g m s}-q_{g m s}^{*}\right]+\sum_{s=1}^{S} \sum_{k=1}^{K} \sum_{t=1}^{T}\left[\frac{\partial c_{s k}^{t}\left(q_{s k}^{t *}\right)}{\partial q_{s k}^{t}}+\hat{c}_{s k}^{t}\left(Q^{2 *}\right)\right] \\
& \quad \times\left[q_{s k}^{t}-q_{s k}^{t *}\right]-\sum_{k=1}^{K} \rho_{3 k}\left(d^{*}\right) \times\left[d_{k}-d_{k}^{*}\right] \geqslant 0 \quad \forall\left(q, h, Q^{1}, Q^{2}, d\right) \in \mathscr{K}^{5} .
\end{aligned}
$$

Variational inequality (52) is precisely variational inequality (18) governing the electric power supply chain network equilibrium. Hence, we have the following result:

Theorem 3. A solution $\left(q^{*}, h^{*}, Q^{1^{*}}, Q^{2^{*}}, d^{*}\right) \in \mathscr{K}^{5}$ of the variational inequality (18) governing the electric power supply chain network equilibrium coincides with the (via (35)-(46) and (48)-(49) feasible link flow and travel demand pattern for the supernetwork $\mathscr{G}_{\mathscr{S}}$ constructed above and satisfies variational inequality (51). Hence, it is a transportation network equilibrium according to Theorem 2.

We now discuss the interpretation of the electric power supply chain network equilibrium conditions. These conditions define the electric power supply network equilibrium in terms of paths and path flows, which, as shown above, coincide with Wardrop's (1952) first principle of user-optimization in the context of transportation networks over the network given in Fig. 2. Hence, we now have an entirely new interpretation of electric power supply network equilibrium which states that only minimal cost paths will be used from the super source node 0 to any destination node. Moreover, the cost on the utilized paths for a particular O/D pair is equal to the disutility (or the demand market price) that the users are willing to pay. This interpretation also implies a type of efficiency principle regarding electric power network operation and utilization, which was first noted by Nagurney and Liu (2005) but in much simpler electric power supply chain network models without power plants and pollution taxes.

In Section 5, we will show how Theorem 3 can be utilized to exploit algorithmically the theoretical results obtained above when we compute the equilibrium patterns of numerical electric power supply chain network examples using an algorithm previously used for the computation of elastic demand transportation network equilibria. Of course, existence and uniqueness results obtained for elastic demand transportation network equilibrium models as in Dafermos (1982) as well as stability and sensitivity analysis results (Nagurney and Zhang, 1996) can now be transferred to electric power networks using the formalism/equivalence established above.

It is important to emphasize that the connection formalized above between electric power supply chain networks and transportation networks also unveils opportunities for further modeling enhancements. For example, one may construct network representations of actual power grids and substitute these for the corresponding transmission links in the supernetwork. The concept of equilibrium path flows would still be appropriate and relevant but with the supernetwork expanded accordingly. For example, an analogous extension but in the case of spatial price network equilibrium problems can be found in Dafermos and Nagurney (1984). 


\section{Computations}

In this section, we provide numerical examples to demonstrate how the theoretical results in this paper can be applied in practice. We utilize the Euler method for our numerical computations. The Euler method is induced by the general iterative scheme of Dupuis and Nagurney (1993) and has been applied by Nagurney and Zhang (1996) to solve variational inequality (27) in path flows (equivalently, variational inequality (28) in link flows) (Zhang and Nagurney, 1997). Convergence results can be found in the above references.

\subsection{The Euler method}

For the solution of (27), the Euler method takes the form: at iteration $\tau$ compute the path flows for paths $p \in P$ (and the travel demands) according to

$$
x_{p}^{\tau+1}=\max \left\{0, x_{p}^{\tau}+\alpha_{\tau}\left(\lambda_{w}\left(d^{\tau}\right)-C_{p}\left(x^{\tau}\right)\right)\right\} .
$$

The simplicity of (53) lies in the explicit formula that allows for the computation of the path flows in closed form at each iteration. The demands at each iteration simply satisfy (24) and this expression can be substituted into the $\lambda_{w}(\cdot)$ functions.

The Euler method was implemented in FORTRAN and the computer system used was a Sun system at the University of Massachusetts at Amherst. The convergence criterion utilized was that the absolute value of the path flows between two successive iterations differed by no more than $10^{-4}$. The sequence $\left\{\alpha_{\tau}\right\}$ in the Euler method ((53)) was set to: $\left\{1, \frac{1}{2}, \frac{1}{2}, \frac{1}{3}, \frac{1}{3}, \frac{1}{3}, \ldots\right\}$. The Euler method was initialized by setting the demands equal to 100 for each O/D pair with the path flows equally distributed.

In all the numerical examples, the electric power supply chain network consisted of two power generators, with two power plants each, two power suppliers, one transmission provider, and two demand markets as depicted in Fig. 3. The supernetwork representation which allows for the transformation (as proved in Section 4) to a transportation network equilibrium problem is given also in Fig. 3. Hence, in the numerical examples (see also Fig. 2) we had that: $G=2, M=2, S=2, S^{\prime}=2^{\prime}, K=2$, and $T=1$.

The notation is presented here and in the subsequent examples in the form of the electric power supply chain network equilibrium model of Section 2. We then provide the translations of the equilibrium link flows, and the travel demands (and disutilities) into the equilibrium electric power supply chain flows and prices.

Power Generators

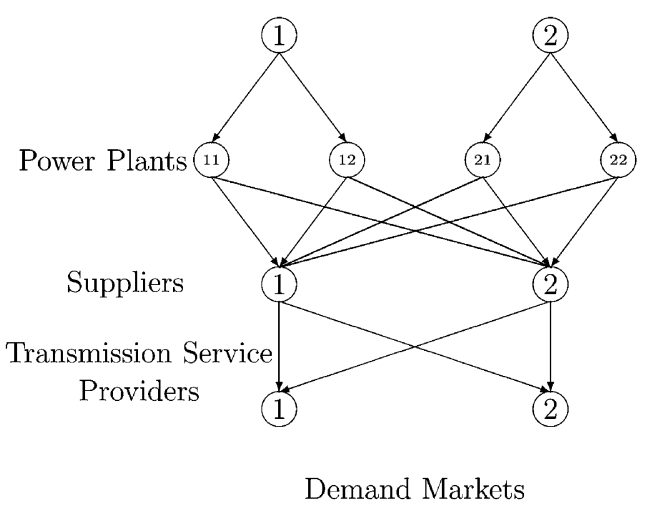

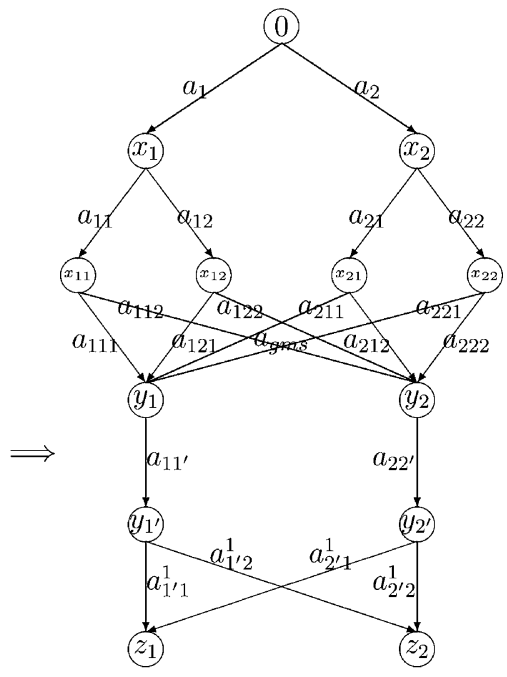

Fig. 3. Electric power network and corresponding supernetwork $\mathscr{G}_{\mathscr{S}}$ for the numerical examples. 
Example 1. The data for the first numerical example is given below. In order to construct a benchmark, we assumed that none of the gencos' power plants were polluting and that, hence, all the terms: $e_{g m}, g=1,2$; $m=1,2$, were equal to zero. Hence, we did not impose any taxes.

The power generating cost functions for the power generators were given by

$$
\begin{aligned}
& f_{11}\left(q_{1}\right)=2.5 q_{11}^{2}+q_{11} q_{21}+2 q_{11}, \quad f_{12}\left(q_{2}\right)=2.5 q_{12}^{2}+q_{11} q_{12}+2 q_{22}, \quad f_{21}\left(q_{1}\right)=.5 q_{21}^{2}+.5 q_{11} q_{21}+2 q_{21}, \\
& f_{22}\left(q_{2}\right)=.5 q_{22}^{2}+q_{12} q_{22}+2 q_{22} .
\end{aligned}
$$

The transaction cost functions faced by the power generators and associated with transacting with the power suppliers were given by

$$
\begin{aligned}
& c_{111}\left(q_{111}\right)=.5 q_{111}^{2}+3.5 q_{111}, \quad c_{112}\left(q_{112}\right)=.5 q_{112}^{2}+3.5 q_{112}, \quad c_{121}\left(q_{121}\right)=.5 q_{121}^{2}+3.5 q_{121}, \\
& c_{122}\left(q_{122}\right)=.5 q_{122}^{2}+3.5 q_{122}, \\
& c_{211}\left(q_{211}\right)=.5 q_{211}^{2}+2 q_{211}, \quad c_{212}\left(q_{212}\right)=.5 q_{212}^{2}+2 q_{212}, \quad c_{221}\left(q_{221}\right)=.5 q_{221}^{2}+2 q_{221}, \\
& c_{222}\left(q_{222}\right)=.5 q_{222}^{2}+2 q_{222} .
\end{aligned}
$$

The operating costs of the power generators, in turn, were given by

$$
c_{1}\left(Q^{1}\right)=.5\left(\sum_{i=1}^{2} q_{i 1}\right)^{2}, \quad c_{2}\left(Q^{1}\right)=.5\left(\sum_{i=1}^{2} q_{i 2}\right)^{2} .
$$

The demand market price functions at the demand markets were

$$
\rho_{31}(d)=-1.33 d_{1}+366.6, \quad \rho_{32}=-1.33 d_{2}+366.6,
$$

and the transaction costs between the power suppliers and the consumers at the demand markets were given by

$$
\hat{c}_{s k}^{1}\left(q_{s k}^{1}\right)=q_{s k}^{1}+5, \quad s=1,2 ; k=1,2 .
$$

All other transaction costs were assumed to be equal to zero.

We utilized the supernetwork representation of this example depicted in Fig. 3 with the links enumerated as in Fig. 3 in order to solve the problem via the Euler method. Note that there are 13 nodes and 20 links in the supernetwork in Fig. 3. Using the procedure outlined in Section 4, we defined O/D pair $w_{1}=\left(0, z_{1}\right)$ and O/D pair $w_{2}=\left(0, z_{2}\right)$ and we associated the $\mathrm{O} / \mathrm{D}$ pair travel disutilities with the demand market price functions as in (49) and the user link travel cost functions as given in (42)-(46) (analogous constructions were done for the subsequent examples).

The Euler method converged in 67 iterations and yielded the equilibrium link flows (also the supernetwork in Fig. 3):

$$
\begin{aligned}
& f_{a_{1}}^{*}=32.53, \quad f_{a_{2}}^{*}=115.22, \\
& f_{a_{11}}^{*}=22.57, \quad f_{a_{12}}^{*}=9.96, \quad f_{a_{21}}^{*}=22.90, \quad f_{a_{22}}^{*}=92.32, \\
& f_{a_{1^{\prime}}}^{*}=f_{a_{22^{\prime}}}^{*}=73.87, \\
& f_{a_{111}}^{*}=11.29, \quad f_{a_{112}}^{*}=11.29, \quad f_{a_{121}}^{*}=4.98, \quad f_{a_{122}}^{*}=4.98, \\
& f_{a_{211}}^{*}=11.45, \quad f_{a_{212}}^{*}=11.45, \quad f_{a_{221}}^{*}=46.16, \quad f_{a_{222}}^{*}=46.16, \\
& f_{a_{1^{\prime} 1}^{1}}^{*}=f_{a_{1^{\prime} 2}^{1}}^{*}=f_{a_{2^{\prime} 1}^{1}}^{*}=f_{a_{2^{\prime} 2}}^{*}=36.94,
\end{aligned}
$$

and the following travel demands: $d_{w_{1}}^{*}=73.88, d_{w_{2}}^{*}=73.88$.

The incurred travel disutilities were $\lambda_{w_{1}}=\lambda_{w_{2}}=268.36$. We do not report the path flows due to space limitations (there are eight paths connecting each O/D pair) but note that all paths connecting each O/D pair were used, that is, had positive flow and the travel costs for paths connecting each O/D pair were equal to the travel disutility for that O/D pair. 
We now provide the translations of the above equilibrium flows into the electric power supply chain network flow and price notation using (40)-(43) and (45)-(49).

The electric power supply chain network flows were

$$
\begin{aligned}
& q_{1}^{*}=32.53, \quad q_{2}^{*}=115.22, \\
& q_{11}^{*}=22.57, \quad q_{12}^{*}=9.96, \quad q_{21}^{*}=22.90, \quad q_{22}^{*}=9.96, \\
& h_{1}^{*}=h_{2}^{*}=73.87, \\
& q_{111}^{*}=11.29, \quad q_{112}^{*}=11.29, \quad q_{121}^{*}=4.98, \quad q_{122}^{*}=4.98, \\
& q_{211}^{*}=11.45, \quad q_{212}^{*}=11.45, \quad q_{221}^{*}=46.16, \quad q_{222}^{*}=46.16, \\
& q_{1^{\prime} 1}^{1 *}=q_{1^{\prime} 2}^{1 *}=q_{2^{\prime} 1}^{1 *}=q_{2^{\prime} 2}^{1 *}=36.94 .
\end{aligned}
$$

The demand prices at the demand markets were $\rho_{31}=\rho_{32}=268.36$ and the demands were $d_{1}^{*}=d_{2}^{*}=73.88$. The optimality/equilibrium conditions were satisfied with excellent accuracy.

Since we assumed that $e_{g m}=0, g=1,2 ; m=1,2$, the total carbon emissions: $\mathrm{TE}=0$.

Example 2. We then solved a variant of Example 1. We kept the data identical to that in Example 1 except that we considered power plant 1 of genco 1 to be polluting with $e_{11}=1$. Our goal was to identify a tax high enough so that the polluting power plant would not produce at all, which means that the corresponding equilibrium link flow would be zero. By setting $\tau_{11}=133$ (determined through simulations) we obtained that $f_{a_{11}}^{*}=0$, which means that this pollution tax was sufficiently high enough that the genco did not use the polluting plant at all.

The Euler method converged in 65 iterations and yielded the following equilibrium link flows (Fig. 3):

$$
\begin{aligned}
& f_{a_{1}}^{*}=10.77, \quad f_{a_{2}}^{*}=128.71, \\
& f_{a_{11}}^{*}=0.00, \quad f_{a_{12}}^{*}=10.77, \quad f_{a_{21}}^{*}=29.14, \quad f_{a_{22}}^{*}=99.58, \\
& f_{a_{11^{\prime}}}^{*}=f_{a_{22^{\prime}}}^{*}=69.74, \\
& f_{a_{111}}^{*}=0.00, \quad f_{a_{112}}^{*}=0.00, \quad f_{a_{121}}^{*}=5.38, \quad f_{a_{122}}^{*}=5.38, \\
& f_{a_{211}}^{*}=14.57, \quad f_{a_{212}}^{*}=14.57, \quad f_{a_{221}}^{*}=49.79, \quad f_{a_{222}}^{*}=49.79, \\
& f_{a_{1^{\prime} 1}}^{*}=f_{a_{1^{\prime} 2}}^{*}=f_{a_{2^{\prime} 1}}^{1}=f_{a_{2^{\prime} 2}}^{*}=34.87,
\end{aligned}
$$

and the following travel demands: $d_{w_{1}}^{*}=d_{w_{2}}^{*}=69.74$.

The incurred travel disutilities were $\lambda_{w_{1}}=\lambda_{w_{2}}=273.85$ and the equilibrium demands were $d_{w_{1}}^{*}=d_{w_{2}}^{*}=69.74$.

Although we do not report the equilibrium path flows, due to space constraints, we note that, in this example, two paths connecting each O/D pair were not used; in other words, they had flows of zero on them.

For completeness, we provide the translations of the above equilibrium flows into the electric power supply chain network flow and price notation using (40)-(43) and (45)-(49).

The electric power supply chain network flows were

$$
\begin{aligned}
& q_{1}^{*}=10.77, \quad q_{2}^{*}=128.71, \\
& q_{11}^{*}=0.00, \quad q_{12}^{*}=10.77, \quad q_{21}^{*}=29.14, \quad q_{22}^{*}=99.58, \\
& h_{1}^{*}=h_{2}^{*}=69.74, \\
& q_{111}^{*}=0.00, \quad q_{112}^{*}=0.00, \quad q_{121}^{*}=5.38, \quad q_{122}^{*}=5.38, \\
& q_{211}^{*}=11.45, \quad q_{212}^{*}=14.57, \quad q_{221}^{*}=49.79, \quad q_{222}^{*}=49.79, \\
& q_{1^{\prime} 1}^{1 *}=q_{1^{\prime} 2}^{1 *}=q_{2^{\prime} 1}^{1 *}=q_{2^{\prime} 2}^{1 *}=34.87 .
\end{aligned}
$$

The demand prices at the demand markets were $\rho_{31}=\rho_{32}=273.85$ and the demands were $d_{1}^{*}=d_{2}^{*}=69.74$.

Note that, with the imposition of the pollution tax, the demand for electric power was reduced and the price of electric power increased. 
The total emissions generated were due to the first power plant of the first genco with $\mathrm{TE}_{1}=e_{11} q_{11}^{*}=0$. We note that if no carbon tax had been imposed then $\mathrm{TE}_{1}=22.57$, and the demand would have been equal to 73.88 and the demand market price to 268.36 at each of the two demand markets.

Example 3. Example 3 was constructed from Example 2. The data were identical to the data in Example 2, except that we now assumed that the first power plant of genco 2 was also polluting with $e_{21}=1$. We imposed the same tax on the first power plant of the second genco as we had for power plant 1 of genco 1 . Hence, in this example, all taxes were equal to zero except that $\tau_{11}=\tau_{21}=133$.

The Euler method converged in 67 iterations and yielded the following new equilibrium pattern: The computed equilibrium link flows were now:

$$
\begin{aligned}
& f_{a_{1}}^{*}=17.42, \quad f_{a_{2}}^{*}=113.36, \\
& f_{a_{11}}^{*}=5.80, \quad f_{a_{12}}^{*}=11.61, \quad f_{a_{21}}^{*}=6.14, \quad f_{a_{22}}^{*}=107.22, \\
& f_{a_{11^{\prime}}}^{*}=f_{a_{22^{\prime}}}^{*}=65.39, \\
& f_{a_{111}}^{*}=2.90, \quad f_{a_{112}}^{*}=2.90, \quad f_{a_{121}}^{*}=5.81, \quad f_{a_{122}}^{*}=5.81, \\
& f_{a_{211}}^{*}=3.07, \quad f_{a_{212}}^{*}=3.07, \quad f_{a_{221}}^{*}=53.61, \quad f_{a_{222}}^{*}=53.61, \\
& f_{a_{1^{\prime} 1}^{1}}^{*}=f_{a_{1^{\prime}}}^{*}=f_{a_{2^{\prime} 1}^{1}}^{*}=f_{a_{2^{\prime} 2}}^{*}=32.69,
\end{aligned}
$$

and the following travel demands: $d_{w_{1}}^{*}=d_{w_{2}}^{*}=65.39$. The incurred travel disutilities were $\lambda_{w_{1}}=\lambda_{w_{2}}=279.63$.

In this example (as in Example 1), all paths connecting each O/D pair were used, that is, they had positive equilibrium flows.

The electric power supply chain network flows/transactions were

$$
\begin{aligned}
& q_{1}^{*}=17.42, \quad q_{2}^{*}=113.36, \\
& q_{11}^{*}=5.80, \quad q_{12}^{*}=11.61, \quad q_{21}^{*}=6.14, \quad q_{22}^{*}=107.22, \\
& h_{1}^{*}=h_{2}^{*}=65.39, \\
& q_{111}^{*}=2.90, \quad q_{112}^{*}=2.90, \quad q_{121}^{*}=5.81, \quad q_{122}^{*}=5.81, \\
& q_{211}^{*}=3.07, \quad q_{212}^{*}=3.07, \quad q_{221}^{*}=53.61, \quad q_{222}^{*}=53.61, \\
& q_{1^{\prime} 1}^{1 *}=q_{1^{\prime} 2}^{1 *}=q_{2^{\prime} 1}^{1 *}=q_{2^{\prime} 2}^{1 *}=32.69 .
\end{aligned}
$$

The demand prices at the demand markets were $\rho_{31}=\rho_{32}=279.63$, with demands of $d_{1}^{*}=d_{2}^{*}=65.39$.

The imposition of the same tax on the polluting power plants of both power generators had the effect that both these power plants produced electric power. In Example 2, in contrast, the imposition of a single tax resulted in no production at the polluting power plant, whereas keeping that tax and imposing the same tax also on another power plant resulted in production in the former plant. However, the polluting power plant of genco 2 did reduce its production substantially in plant 1 as compared to what it produced there in Example 2. The demand market prices at the two demand markets were now higher than in Example 2 and the demand for electric power was lower in both demand markets (due to the higher prices as a consequence of the pollution taxes). The total pollution generated was: $\mathrm{TE}=\mathrm{TE}_{1}+\mathrm{TE}_{2}=5.80+6.14=11.94$. Notice that the total amount of carbon emitted, relative to the amount emitted in Example 2, was essentially reduced by $50 \%$.

Example 4. In Example 4, we then set out to ask the question, what would be the effects of imposing the same tax on all the genco/power plants, assuming that $e_{g m}=1$ for $g=1,2 ; m=1,2$. In this example, we set $\tau_{g m}=133$ for $g=1,2$ and $m=1,2$.

The Euler method converged in 65 iterations. The computed equilibrium link flows were now:

$$
\begin{aligned}
& f_{a_{1}}^{*}=20.24, \quad f_{a_{2}}^{*}=72.50, \\
& f_{a_{11}}^{*}=14.09, \quad f_{a_{12}}^{*}=6.15, \quad f_{a_{21}}^{*}=14.42, \quad f_{a_{22}}^{*}=58.05,
\end{aligned}
$$




$$
\begin{aligned}
& f_{a_{11^{\prime}}}^{*}=f_{a_{22^{\prime}}}^{*}=46.37, \\
& f_{a_{111}}^{*}=7.04, \quad f_{a_{112}}^{*}=7.04, \quad f_{a_{121}}^{*}=3.08, \quad f_{a_{122}}^{*}=3.08, \\
& f_{a_{211}}^{*}=7.21, \quad f_{a_{212}}^{*}=7.21, \quad f_{a_{221}}^{*}=29.04, \quad f_{a_{222}}^{*}=29.04, \\
& f_{a_{1^{\prime} 1}^{1}}^{*}=f_{a_{1^{\prime} 2}}^{*}=f_{a_{2^{\prime} 1}^{1}}^{*}=f_{a_{2^{\prime} 2}}^{*}=23.18,
\end{aligned}
$$

and the following travel demands:

$$
d_{w_{1}}^{*}=d_{w_{2}}^{*}=46.37 \text {. }
$$

The incurred travel disutilities were $\lambda_{w_{1}}=\lambda_{w_{2}}=304.93$.

In this example, all paths (as in Examples 1 and 3) were used in equilibrium, that is, they had positive flows.

The electric power supply chain network flows/transactions were

$$
\begin{aligned}
& q_{1}^{*}=20.24, \quad q_{2}^{*}=72.50, \\
& q_{11}^{*}=14.09, \quad q_{12}^{*}=6.15, \quad q_{21}^{*}=14.42, \quad q_{22}^{*}=58.05, \\
& h_{1}^{*}=h_{2}^{*}=46.37, \\
& q_{111}^{*}=7.04, \quad q_{112}^{*}=7.04, \quad q_{121}^{*}=3.08, \quad q_{122}^{*}=3.08, \\
& q_{211}^{*}=7.21, \quad q_{212}^{*}=7.21, \quad q_{221}^{*}=29.04, \quad q_{222}^{*}=29.04, \\
& q_{1^{\prime} 1}^{1 *}=q_{1^{\prime} 2}^{1 *}=q_{2^{\prime} 1}^{1 *}=q_{2^{\prime} 2}^{1 *}=23.18 .
\end{aligned}
$$

The demand prices at the demand markets were

$$
\rho_{31}=\rho_{32}=304.93 \text {, }
$$

and the demands for electric power were now: $d_{1}^{*}=d_{2}^{*}=46.37$.

The imposition of a pollution tax on all the power plants results in a substantial increase in demand market prices and a decrease in demand for electric power.

The total amount of emissions: $\mathrm{TE}=\mathrm{TE}_{1}+\mathrm{TE}_{2}=92.71$, where $\mathrm{TE}_{1}=14.09+6.15=20.24$ and $\mathrm{TE}_{2}=14.42+58.05=72.47$. If we had not imposed the taxes, the total amount of emissions would have been 147.23 and the demand would have been 73.88 and the demand market price would have been equal to 268.36 at each demand market.

Example 5. In Example 5, our goal was to identify how high the taxes should be on the first (assumed to be polluting) power plants of each generator so that neither high-polluting power plant would be used. In Example 3, if we imposed taxes: $\tau_{11}=\tau_{21}=133$, then the first power plant of each genco was still producing. We, hence, conducted the following simulation: we increased the taxes from 133 for both those power plants (thus, we used as the baseline Example 3) until we achieved zero production at those power plants. Taxes of $\tau_{11}=\tau_{21}=188$ yielded the desired policy result that there was zero production at the noxious power plants.

The complete equilibrium solution is now reported. The Euler method converged in 62 iterations and yielded the following equilibrium solution: The computed equilibrium link flows were now:

$$
\begin{aligned}
& f_{a_{1}}^{*}=12.20, \quad f_{a_{2}}^{*}=112.53, \\
& f_{a_{11}}^{*}=0.00, \quad f_{a_{12}}^{*}=12.20, \quad f_{a_{21}}^{*}=0.00, \quad f_{a_{22}}^{*}=112.53, \\
& f_{a_{11^{\prime}}}^{*}=f_{a_{22^{\prime}}}^{*}=62.37, \\
& f_{a_{111}}^{*}=0.00, \quad f_{a_{112}}^{*}=0.00, \quad f_{a_{121}}^{*}=6.10, \quad f_{a_{122}}^{*}=6.10, \\
& f_{a_{211}}^{*}=0.00, \quad f_{a_{212}}^{*}=0.00, \quad f_{a_{221}}^{*}=56.26, \quad f_{a_{222}}^{*}=56.26, \\
& f_{a_{1^{\prime} 1}}^{*}=f_{a_{1^{\prime}}}^{*}=f_{a_{2^{\prime} 1}^{1}}^{*}=f_{a_{2^{\prime} 2}}^{*}=31.18,
\end{aligned}
$$

and the following travel demands:

$$
d_{w_{1}}^{*}=d_{w_{2}}^{*}=62.37 \text {. }
$$

The incurred travel disutilities were $\lambda_{w_{1}}=\lambda_{w_{2}}=283.60$. 
In this example, four paths (that is, half of the paths) connecting each O/D pair had zero flow in equilibrium (and, hence, were not used) and this is because their path travel costs exceeded the equilibrium path costs of the used paths (and the travel disutilities for the respective O/D pair).

The electric power flows/transactions were

$$
\begin{aligned}
& q_{1}^{*}=12.20, \quad q_{2}^{*}=112.53, \\
& q_{11}^{*}=0.00, \quad q_{12}^{*}=12.20, \quad q_{21}^{*}=0.00, \quad q_{22}^{*}=112.53, \\
& h_{1}^{*}=h_{2}^{*}=62.37, \\
& q_{111}^{*}=0.00, \quad q_{112}^{*}=0.00, \quad q_{121}^{*}=6.10, \quad q_{122}^{*}=6.10, \\
& q_{211}^{*}=0.00, \quad q_{212}^{*}=0.00, \quad q_{221}^{*}=56.26, \quad q_{222}^{*}=56.26, \\
& q_{1^{\prime} 1}^{1 *}=q_{1^{\prime} 2}^{1 *}=q_{2^{\prime} 1}^{1 *}=q_{2^{\prime} 2}^{1 *}=31.18 .
\end{aligned}
$$

The demand prices at the demand markets were $\rho_{31}=\rho_{32}=283.60$, with demands of $d_{1}^{*}=d_{2}^{*}=62.37$.

The numerical examples illustrate some of the types of simulations that can be conducted in order to investigate the ramification of the imposition of pollution taxes.

\section{Conclusions}

In this paper, we proposed a new model of electric power supply chain networks with distinct power plants, which allows for distinct fuels. The model also includes carbon pollution taxes that can be imposed on the various power generator/power plant combinations. We derived the optimality conditions of the decisionmakers and proved that the governing equilibrium conditions satisfy a variational inequality problem. We then demonstrated that the electric power supply chain network equilibrium problem can be reformulated as a transportation network equilibrium problem with elastic demands over an appropriately constructed abstract network or supernetwork (see also Boyce et al. (2005)).

Specifically, we utilized variational inequality theory to establish the equivalence between the electric power supply chain network equilibrium problem in which there are multiple power plants associated with each power generator (or genco) with assigned pollution taxes and a transportation network equilibrium problem with elastic demands over a specially-constructed supernetwork. The theoretical results established in this paper were then exploited in the computation of electric power supply chain numerical examples with distinct pollution taxes which were solved as reformulated transportation network equilibrium problems. The numerical examples illustrate the flexibility of assigning taxes in achieving such desired outcomes as zero production in the highest polluting power plants. This paper further confirms a hypothesis of Beckmann et al. (1956) that electric power generation and distribution networks are related to transportation network equilibrium problems; see also McGuire (1997, 1999). For the analogous equivalence, but for multitiered supply chain network problems, see Nagurney (in press).

\section{Acknowledgements}

This research of the second and third authors was supported, in part, by NSF Grant No. IIS 00026471. The research of the second author was also supported, in part, by the Radcliffe Institute for Advanced Study at Harvard University under its 2005-2006 Radcliffe Fellows Program. This support is gratefully acknowledged and appreciated. The authors would like to sincerely thank the anonymous reviewer for very helpful comments and suggestions on an earlier version of this paper.

\section{References}

Baranzini, A., Goldemberg, J., Speck, S., 2000. A future for carbon taxes. Ecological Economics 32, 395-412. Bazaraa, M.S., Sherali, H.D., Shetty, C.M., 1993. Nonlinear Programming: Theory and Algorithms. John Wiley \& Sons, New York. Beckmann, M.J., McGuire, C.B., Winsten, C.B., 1956. Studies in the Economics of Transportation. Yale University Press, New Haven. Bertsekas, D.P., Tsitsiklis, J.N., 1989. Parallel and Distributed Computation-Numerical Methods. Prentice-Hall, Englewood Cliffs, NJ. 
Boyce, D.E., Mahmassani, H.S., Nagurney, A., 2005. A retrospective on Beckmann, McGuire, and Winsten's studies in the economics of transportation. Papers in Regional Science 84, 85-103.

Casazza, J., Delea, F., 2003. Understanding Electric Power Systems. John Wiley \& Sons, New York.

Cline, W.R., 1992. The economics of global warming. Institute for International Economics, Washington, DC.

Dafermos, S., 1982. The general multimodal network equilibrium problem with elastic demand. Networks 12, 57-72.

Dafermos, S., Nagurney, A., 1984. Sensitivity analysis for the general spatial economic equilibrium problem. Operations Research 32, 1069-1086.

Dafermos, S., Nagurney, A., 1987. Oligopolistic and competitive behavior of spatially separated markets. Regional Science and Urban Economics 17, 245-254.

Dupuis, P., Nagurney, A., 1993. Dynamical systems and variational inequalities. Annals of Operations Research 44, 9-42.

Edison Electric Institute, 2000. Statistical yearbook of the electric utility industry 1999, Washington, DC.

Energy Information Administration, 2000. Electric power annual 1999, vol. II, DOE/EIA-0348 (99)/2, Washington, DC.

Energy Information Administration, 2005. Annual energy review 2004, DOE/EIA-0348 (2000), Washington, DC.

Gabay, D., Moulin, H., 1980. On the uniqueness and stability of Nash equilibria in noncooperative games. In: Bensoussan, A., Kleindorfer, P., Tapiero, C.S. (Eds.), Applied Stochastic Control in Econometrics and Management Science. North-Holland, Amsterdam.

McGuire, B., 1997. Price Driven Coordination in a Lossy Power GridPWP-045. California Energy Institute, Berkeley.

McGuire, B., 1999. Power-Grid Decentralization. California Energy Institute, Berkeley, PWP-061.

Nagurney, A., 1993. Network Economics: A Variational Inequality Approach. Kluwer, Dordrecht.

Nagurney, A., in press. On the relationship between supply chain and transportation network equilibria: a supernetwork equivalence with computations. Transportation Research E.

Nagurney, A., Dong, J., Zhang, D., 2002. A supply chain network equilibrium model. Transportation Research E 38, $281-303$.

Nagurney, A., Liu, Z., 2005. Transportation Network Equilibrium Reformulations of Electric Power Networks with Computations. Isenberg School of Management, University of Massachusetts, Amherst. Available from: http://supernet.som.umass.edu.

Nagurney, A., Matsypura, D., 2004. A supply chain network perspective for electric power generation, supply, transmission, and consumption. In: Proceedings of the International Conference on Computing, Communications and Control Technologies, vol. VI, Austin, Texas, pp. 127-134.

Nagurney, A., Toyasaki, F., 2003. Supply chain supernetworks and environmental criteria. Transportation Research D 8, $185-213$.

Nagurney, A., Zhang, D., 1996. Projected Dynamical Systems and Variational Inequalities with Applications. Kluwer, Boston.

Nash, J.F., 1950. Equilibrium points in $n$-person games. Proceedings of the National Academy of Sciences 36, 48-49.

Nash, J.F., 1951. Noncooperative games. Annals of Mathematics 54, 286-298.

Painuly, J.P., 2001. Barriers to renewable energy penetration; a framework for analysis. Renewable Energy $24,73-89$.

Poterba, J., 1993. Global warming policy: a public finance perspective. Journal of Economic Perspectives 7, 73-89.

RECS, 1999. Renewable energy certificate system, <http://www.recs.org $>$.

Schaeffer, G.J., Boots, M.G., Martens, J.W., Voogt, M.H., 1999. Tradable green certificates: a new market-based incentive scheme for renewable energy. Energy Research Centre of the Netherlands (ECN) Report, ECN-I-99-004.

Singh, H. (Ed.), 1999. IEEE Tutorial on Game Theory Applications in Power Systems. IEEE.

Wardrop, J.G., 1952. Some theoretical aspects of road traffic research. In: Proceedings of the Institution of Civil Engineers, Part II, pp. $325-378$.

Zaccour, G. (Ed.), 1998. Deregulation of Electric Utilities. Kluwer, Boston.

Zhang, D., Nagurney, A., 1997. Formulation, stability, and computation of traffic network equilibria as projected dynamical systems. Journal of Optimization Theory and Applications 93, 417-444. 